\title{
Dysregulation of CD69 by overexpression of microRNA-367-3p associated with post-myocardial infarction cardiac fibrosis
}

\author{
HAIYAN HU, JING LI and JINGFANG ZHANG
}

\begin{abstract}
Department of Ultrasound, The Second Affiliated Hospital of Xi'an Medical College, Xi'an, Shaanxi 710038, P.R. China
\end{abstract}
Received April 27, 2016; Accepted May 9, 2017

DOI: $10.3892 / \mathrm{mmr} .2018 .9234$

\begin{abstract}
Cardiac fibrosis is characterized as net accumulation of ECM (extracellular matrix) proteins in the cardiac interstitium, which contributes to dysfunction of both systolic and diastolic. The present study aimed to identify the association between microRNA (miR)-367-3p and cluster of differentiation 69 (CD69), and their roles in regulating the development of cardiac fibrosis. Participants $(n=34)$ were enrolled and diagnosed with cardiac fibrosis [fibrosis $(+)$; $\mathrm{n}=16$ ] or non-fibrosis control [fibrosis $(-) ; n=18$ ]. In-silicon analysis and luciferase assay were used to identify CD69 as a target of miR-367-3p. Reverse transcription-quantitative polymerase chain reaction (RT-qPCR) and western blot analysis were used to determine the expression level of miR-367-3p and CD69 mRNA and protein, in patient groups or cells transfected with miR-367-3p mimics or inhibitors. Cytokine assays were used to detect the level of interleukin (IL)-17, tumor necrosis factor (TNF)- $\alpha$, interferon (IFN)- $\gamma$ and granulocyte macrophage colony-stimulating factor. Flow cytometry was used to detect the T helper (Th)-17 fraction of cells in different treatment groups. Analysis by RT-qPCR indicated that the expression of miR-367-3p was decreased in the cardiac fibrosis (+) group compared with the fibrosis (-) control group. In contrast, the level of CD69 mRNA was increased in the cardiac fibrosis group compared with the control group. The CD69 3'-untranslated region (UTR) contained two potential seed regions for miR-367-3p and was therefore predicted as a target. A dual-luciferase reporter assay demonstrated a reduced luciferase activity of cells transfected with wild-type CD69 3'-UTR and the mutant2 CD69 3'-UTR, however, the mutant1 CD69 3'-UTR completely abolished the interaction with miR-367-3p. Furthermore, the CD69 mRNA and protein expression levels in cells transfected with miR-367-3p mimics and CD69 siRNA
\end{abstract}

Correspondence to: Dr Haiyan Hu, Department of Ultrasound, The Second Affiliated Hospital of Xi'an Medical College, 167 Fandong Street, Baqiao, Xi'an, Shaanxi 710038, P.R. China E-mail: cd69fibrosis@126.com

Key words: cluster of differentiation-69, microRNA-367-3p, myocardial infarction, cardiac fibrosis were downregulated compared with the scramble control. Cytokine analysis demonstrated increased levels of IL-17 and TNF- $\alpha$ in cells transfected with miR-367-3p mimics or CD69 siRNA, compared with the scramble control. The IFN- $\gamma$ and GM-CSF levels of cells transfected with pcDNA3-CD69, miR-367-3p mimics or miR-367-3p + pcDNA3-CD69 were comparable with the scramble control. Notably, the Th17 fraction of cells was upregulated following the introduction of miR-367-3p mimics or CD69 siRNA. In conclusion, these results provide evidence that a decrease in miR-367-3p levels may be associated with cardiac fibrosis.

\section{Introduction}

Characterized by a net accumulation of extracellular matrix in the myocardium, cardiac fibrosis serves as a key element of several heart disease pathologies (1). As the regenerative capacity of the mammalian myocardium remains negligible, the most extensive ventricular fibrotic remodeling occurs in conditions associated with acute cardiomyocyte death. Following the onset of acute myocardial infarction (MI), an inflammatory reaction is induced by the sudden loss of a large number of cardiomyocytes, ultimately resulting in the formation of a collagen-based scar in place of the dead myocardium $(2,3)$.

Cardiac fibrosis following MI, which may determine ventricular size, shape and wall thickness, exerts a marked influence on cardiac function during the development of heart failure (4). Excessive fibrosis may result in ventricular dilation, expansion of the infarct and subsequent heart failure (5). During the process of cardiac remodeling, fibroblasts transform into myofibroblasts, which are fast proliferating $\alpha$-smooth muscle actin-positive cells with marked secretory and contractile properties. Notably, transforming growth factor (TGF)- $\beta$ may induce the formation of myofibroblasts, a process that subsequently results in matrix deposition $(4,6,7)$.

MicroRNAs (miRNAs) are 22 nucleotides in length and are a group of important regulatory RNAs that alter gene expression post-transcriptionally. MiRNAs bind to the 3'untranslated region (UTR) of mRNAs and result in message degradation or translation blockade, a process which is mediated by the RNA-induced silencing complex (8). The small-RNA family includes miRNAs and small interfering RNAs (siRNAs); this family was discovered a decade ago and the members demonstrate a common structure. There are 
2,578 human microRNAs listed in the latest version (v20.0) of miRBase.org, the central repository database for miRNAs (9). MiRNAs have been discovered in the whole genome, with transcriptional units in polycistronic microRNA clusters comprising of 2-50 microRNAs. The regulatory mechanisms of miRNAs are performed by variable or ubiquitous expression in different cell types and tissues (10).

Cluster of differentiation (CD)69 is a C-type lectin classified as a disulfide-linked homodimeric membrane protein (11). The CD69 gene is situated within the natural killer (NK) gene complex on human chromosome 12 and mouse chromosome $6(12,13)$. CD69 was originally identified on the surface of activated lymphocytes, and is a marker antigen expressed at early phases of cellular activation (14-16). However, the expression of CD69 is not strictly limited to these cells; activated eosinophils, neutrophils and macrophages additionally express CD69 (17-19). Furthermore, antibody crosslinking of CD69 has been associated with promoting a number of cellular responses, including natural killer (NK) cell cytotoxicity, production and release of $\mathrm{TNF}-\alpha, \mathrm{T}$ cell proliferation, neutrophil degranulation and production of nitric oxide (NO) $(17,18,20-23)$. Therefore, CD69 may serve a pro-inflammatory function and participate in the pathogenesis of inflammatory diseases, including pulmonary fibrosis.

It has previously been demonstrated that miR-367-3p is differentially expressed in fibroblast cells collected from post-MI cardiac fibrosis, and dysregulation of CD69 may be involved in fibroblast cell apoptosis (24,25). By searching online miRNA databases, CD69 was identified as a hypothetical target of miR-367-3p. The present study validated CD69 as a target of miR-367-3p, and investigated the involvement of miR-367-3p and CD69 in the development of post-MI cardiac fibrosis.

\section{Materials and methods}

Patients. A total of 34 male patients were recruited from the Department of Ultrasound, The second Affiliated Hospital of Xi'an Medical College (Xi'an, China), between November 2013 and December 2014. Details of the patients are included in Table I. The cohort included 16 MI patients with cardiac fibrosis and $18 \mathrm{MI}$ patients without cardiac fibrosis. Written informed consent was obtained prior to open-heart surgery for bypass grafting, and general surgical procedures, during which the tip of the right atrial appendage was removed. All biopsies at the tip of the right atrial appendage were carried out at the same site, and all the samples were stored in liquid nitrogen until further analysis. The ethics committee of the Second Affiliated Hospital of Xi'an Medical College approved the protocols of the study, and the research process was completed in conformity with the last version of the Declaration of Helsinki.

Cell culture and transfection. Fibroblast cells 3T3 were obtained from Chinese Academy of Sciences Cell Bank (Shanghai, China), and were cultured in Dulbecco's modified Eagle's medium/F12 (DMEM; Invitrogen; Thermo Fisher Scientific, Inc., Waltham, MA, USA) supplemented with $10 \%(\mathrm{v} / \mathrm{v})$ fetal bovine serum (Hyclone, Logan, Utah, US), $100 \mu \mathrm{g} / \mathrm{ml}$ streptomycin and 100 units $/ \mathrm{ml}$ penicillin
(Gibco; Thermo Fisher Scientific, Inc.), and maintained in $5 \% \mathrm{CO}_{2} / 95 \%$ air at $37^{\circ} \mathrm{C}$. Fibroblast cells were transferred into 6 -well plates $\left(3-6 \times 10^{5}\right.$ cells/well) containing growth medium without antibiotics, for $12 \mathrm{~h}$ prior to transfection. When the cells reached $80 \%$ confluence, Lipofectamine 2000 (Invitrogen; Thermo Fisher Scientific, Inc.) was used to transfect $20 \mathrm{pmol}$ miR-367-3p mimic, CD69 siRNA or pcDNA-CD69, transfection amounts were selected and protocols were performed according to the manufacturer's protocol (100 ng pcDNA-CD69 or pcDNA were transfected into the culture cells and incubated for $20 \mathrm{~min}$. Next the medium was replaced with fresh medium, and the functional analysis was performed $48 \mathrm{~h}$ following the transfection). All RNA oligoribonucleotides were obtained from Genepharma (Shanghai, China). Tests were performed in triplicate, and 3 independent tests were carried out. The sequences were as follows: miR-367-3p mimics, 5'-UAGCUU AUCAGACUGAUGUUGA-3' and 5'-AACAUCAGUCUG AUAAGCUAUU-3'; CD69 siRNA, 5'-GGTGGCCTTGTG ATCAATGAAACT-3' (sense); miR-367-3p inhibitor, 5'-UCA ACAUCAGUCUGAUAAGCUA-3'.

$R N A$ isolation and reverse transcription quantitative polymerase chain reaction ( $R T-q P C R$ ). QIAzol (Qiagen $\mathrm{GmbH}$, Hilden, Germany) was used to harvest the cells following transfection. RNA was extracted from frozen tissue and fibroblast cells using an MiRNeasy Minikit (Qiagen, GmbH), according to the manufacturer's protocol. A NanoDrop ND-100 spectrometer (NanoDrop; Thermo Fisher Scientific, Inc., Pittsburgh, PA, USA) was used to monitor the RNA yield based on the A260/280 ratio, and a 2100 Bioanalyzer (Agilent Technologies, Inc., Santa Clara, CA, USA) was used to assess the RNA Integrity Number (RIN); RNA samples with a RIN $>6$ were accepted for downstream use. RT-qPCR was performed to analyze the expression level of CD69 mRNA. Reverse transcription of cell-derived mRNA into cDNA was performed using Omniscript Reverse transcriptase with Oligo-dT primers (Qiagen $\mathrm{GmbH}$ ), according to the manufacturer's protocol. A StepOne thermal cycler (Applied Biosystems; Thermo Fisher Scientific, Inc.) was used to incubate the reaction mixture as follow: $95^{\circ} \mathrm{C}$ for $15 \mathrm{~min}$ for initial activation, then $94^{\circ} \mathrm{C}$ for $15 \mathrm{sec}$ for denaturation, followed by $55^{\circ} \mathrm{C}$ for $30 \mathrm{sec}$ for annealing, and final $72^{\circ} \mathrm{C}$ for $60 \mathrm{sec}$ for extension. The Transcriptor First Strand cDNA Synthesis kit (Roche Diagnostics GmbH, Mannheim, Germany) was used to reverse transcribe mRNA into cDNA from tissue samples, using $1 \mu \mathrm{g}$ RNA in a $20 \mu \mathrm{l}$ total reaction volume, according to the manufacturer's protocol. qPCR was performed to assess CD69 mRNA levels in fibroblast cells, using 2X Fast SYBRgreen Mastermix (Applied Biosystems; Thermo Fisher Scientific, Inc.). Melting curve analyses and primer blasting were performed to ensure amplification specificity. A TaqMan miRNA assay (A25576; Applied Biosystems; Thermo Fisher Scientific, Inc.) was used to detect miRNA by RT-qPCR. The $2^{-\Delta \Delta \mathrm{Cq}}$ method was used to assess the relative quantification of CD69 mRNA and U6 was used as an endogenous control. All experiments were performed 3 times (26).

Luciferase assay. The 3' UTR sequences of CD69 were amplified by PCR using a carefully designed primer 
Table I. Patient details.

\begin{tabular}{lccr}
\hline Variable & $\begin{array}{c}\text { Myocardioinfarction } \\
\text { cardiac fibrosis (+) }\end{array}$ & $\begin{array}{c}\text { Myocardioinfarction } \\
\text { cardiac fibrosis (-) }\end{array}$ & 18 \\
\hline Number & 16 & $41.22 \pm 7.11$ & 0.786 \\
Age & $42.23 \pm 6.32$ & 8 & 0.897 \\
Hypertension & 6 & 9 & 0.765 \\
Diabetes mellitus & 8 & 5 & 0.877 \\
Smoker & 4 & & 9 \\
\hline
\end{tabular}

(F, 5'-CACCCTGACTTCAAGAGGGC-3' and R, 5'-GGA TGAAGTGGGTGCCGTAG-3'). AmpliTaq Gold DNA Polymerase (Invitrogen; Thermo Fisher Scientific, Inc.) and a QuikChange XL Site-Directed Mutagenesis kit (Stratagene; Agilent Technologies, Inc.) was used to mutate the seed regions, to remove all complementarity to the nucleotides of miR-367-3p, according to the manufacturer's protocol. The PCR and mutagenesis products were inserted into the pMiR report vector (Ambion; Thermo Fisher Scientific, Inc.) using the SacI and SpeI restriction sites. T4 DNA-Ligase (1 U; Invitrogen; Thermo Fisher Scientific, Inc.) was used to ligate the pMiR report vector with the restricted inserts, according to the manufacturer's protocol. $4 \times 10^{5}$ Fibroblast cells were seeded into a 12 -well plate and transfected with the luciferase reporter vector $(0.5 \mu \mathrm{g})$ containing the wild type or mutant target site, together with $0.04 \mu \mathrm{g}$ control vector Plasmid pRL-SV40 (Promega Corporation, Madison, WI). Transfections were performed using Lipofectamine 2000 (Invitrogen; Thermo Fisher Scientific, Inc.), The Dual-Luciferase Reporter Assay System (Promega Corporation) was used to analyze the luciferase activity $48 \mathrm{~h}$ post-transfection, according to the manufacturer's protocol. The supplied Renilla luciferase plasmid served as the endogenous control. Each test was repeated in 3 times.

Cytokine assay. The concentration of IL-17, TNF- $\alpha$, IFN- $\gamma$ and GM-CSF were measured using ELISA assay kits (KAC1591, BMS223-4, KHC4021 and BMS283 respectively; Thermo Fisher Scientific, Inc.), according to the manufacturer's protocol. Hank's Buffered Salt solution with ice-cold $80 \%$ ethanol was used as a fixative for $30 \mathrm{~min}$ on ice. Then a FITC-Annexin V/Propidium Iodide Apoptosis Detection kit (Shanghai Yeasen Biotechnology Co., Ltd., Shanghai, China) was used to stain the cells according to the manufacturer's protocol. A flow cytometer (BD Biosciences, San Jose, CA, USA) was used with FlowJo version 10.4.1 (FlowJo LLC, Ashland, OR, USA) to detect Th71 fraction of cells treated with miR-367-3p, CD69 siRNA or miR-367-3p + pcDNA3-CD69.

Western blot analysis. Fibroblast cells $\left(7 \times 10^{5}\right)$ were seeded into 48-well plates for $24 \mathrm{~h}$, and cultured in DMEM supplemented with $10 \%$ fetal bovine serum. Following transfection with miR-367-3p mimic, cells were washed with cold PBS (Invitrogen; Thermo Fisher Scientific, Inc.), and cells were lysed with lysis buffer (Thermo Fisher Scientific, Inc.) according to the manufacturer's protocol.
Equal amounts of protein lysates $(50 \mu \mathrm{g})$ were separated by 10\% SDS-PAGE (Bio-Rad Laboratories, Inc., Hercules, CA, USA), and electrophoretically transferred to nitrocellulose membranes (GE Healthcare Life Sciences, Chalfont, UK). Membranes were blocked with 5\% non-fat milk in PBS with $0.05 \%$ Tween- 20 for $2 \mathrm{~h}$ at room temperature, and subsequently incubated with an anti- $\beta$-actin antibody (A1978; 1:10,000; Sigma-Aldrich; Merck KGaA, Darmstadt, Germany) or a polyclonal anti-CD69 antibody (ab202909; 1:2,500; Abcam, Cambridge, UK), at $4^{\circ} \mathrm{C}$ for $12 \mathrm{~h}$. Membranes were washed with PBS containing $0.05 \%$ Tween-20, and incubated with horseradish peroxidase-conjugated secondary antibodies (sc-2380; 1:10,000; Santa Cruz Biotechnology, Inc., Dallas, TX, USA) for $2 \mathrm{~h}$ at room temperature. An enhanced chemiluminescence detection kit (Pierce; Thermo Fisher Scientific, Inc.) was used to develop the membranes. All tests were performed in triplicate.

Statistical analysis. MedCalc version 10.3.2 (MedCalc Software bvba, Ostend, Belgium), SPSS software, version 19.0 (IBM SPSS, Armonk, NY, USA) and GraphPad Prism version 5.01 (GraphPad Software, Inc., La Jolla, CA, USA) were used to perform statistical analyses. One-way ANOVA (continuous data comparison between three or more groups), Student's t-test (continuous data comparison between two groups) and Wilcoxon signed rank test (non-continuous data comparison between groups) were used to compare groups. Pearson correlation analysis was used to test the correlation between the groups. Data were presented as the mean \pm standard deviation. $\mathrm{P}<0.05$ was considered to indicate a statistically significant difference. At least 3 independent experiments were performed.

\section{Results}

Determination of miR-367-3p expression patterns between patient groups. Participants were enrolled and diagnosed with cardiac fibrosis [fibrosis $(+) ; n=16$ ] or without fibrosis [fibrosis $(-) ; n=18$ ]. RT-qPCR was used to detect the expression of miR-367-3p and CD69 mRNA in cardiac fibrosis (+) and fibrosis (-) groups. The expression of miR-367-3p (Fig. 1A) was decreased in the cardiac fibrosis (+) group compared with the fibrosis (-) control group. Furthermore, increased CD69 mRNA was observed in the cardiac fibrosis (+) group compared with the fibrosis (-) control group, indicating that miR-367-3p upregulation and CD69 downregulation may be associated with cardiac fibrosis. 
A

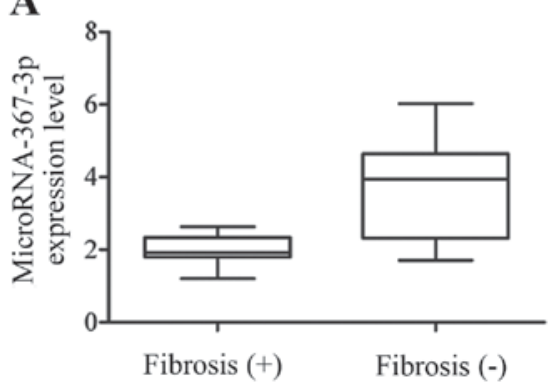

B

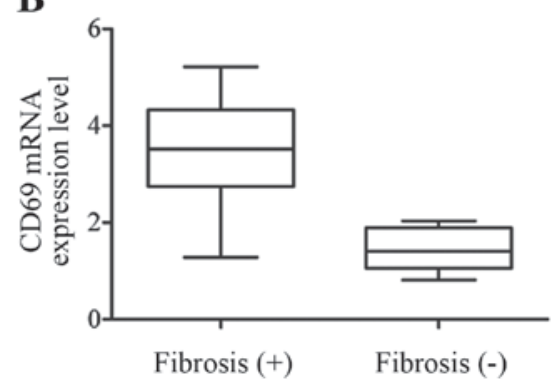

Figure 1. MiR-367-3p is elevated and CD69 mRNA is reduced in patients with cardiac fibrosis. Reverse transcription-quantitative polymerase chain reaction was used to detect the expression of miR-367-3p and CD69 mRNA in patients with and without cardiac fibrosis. (A) The expression level of miR-367-3p was decreased in the patients with cardiac fibrosis [P<0.05 vs. Fibrosis (-)]. (B) The expression level of CD69 mRNA was increased in the patients with cardiac fibrosis $[\mathrm{P}<0.05$ vs. Fibrosis $(-)]$. CD, cluster of differentiation.

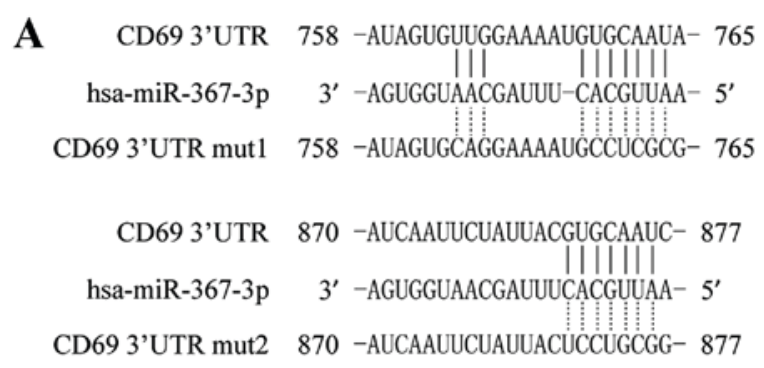

B

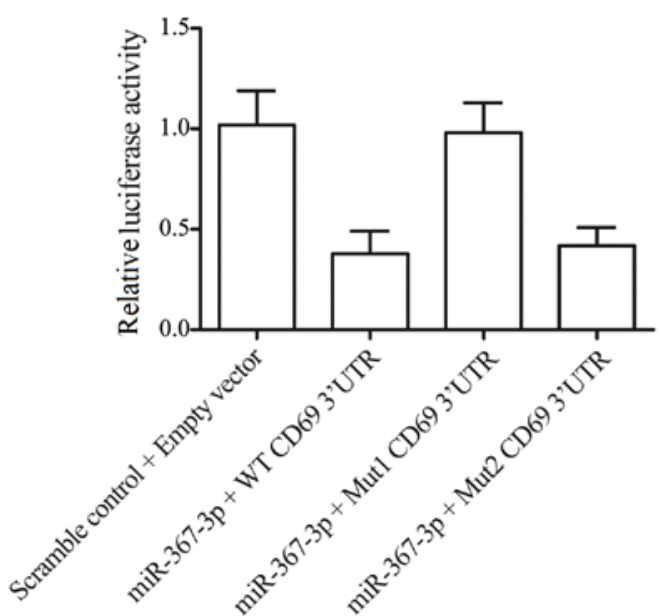

Figure 2. CD69 is a direct target of miR-367-3p. (A) CD69 was identified as a candidate target gene of miR-367-3p. The 3'UTR for CD69 contains two seed sequences for miR-367-3p. (B) Luciferase activity reporter assay was conducted to investigate the association between miR-367-3p and the two theoretical seed regions in the CD69 3'UTR, miR-367-3p mimic reduced luciferase activity of wild-type CD69 3'UTR compared with scramble control $(\mathrm{P}<0.05$ vs. scramble control). $\mathrm{CD}$, cluster of differentiation; miR, microRNA; UTR, untranslated region; WT, wild type; Mut, mutant.

CD69 is a direct target of $\mathrm{miR}-367-3 p$. Hypothetical target genes of miR-367-3p were investigated using the publicly available databases TargetScan (www.targetscan.org/) and miRanda (www.microrna.org/microrna/home.do). CD69 was identified as a candidate target gene, with two potential binding sites in the 3'UTR of CD69 (Fig. 2A). A luciferase activity reporter assay was performed using fibroblast cells, which revealed decreased luciferase activity of cells co-transfected with miR-367-3p mimic and wild-type CD69 3'UTR, or miR-367-3p mimic and mutant2 CD69

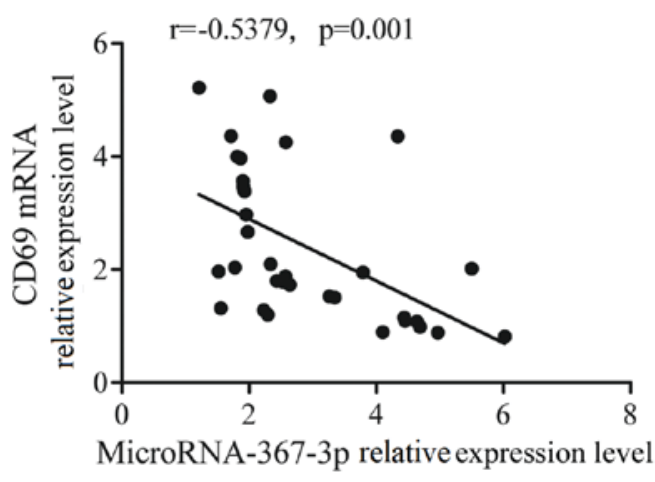

Figure 3. miR-367-3p and CD69 exhibit a negative association. The expression of miR-367-3p and CD69 mRNA were measured in fibroblast cells using reverse transcription-quantitative polymerase chain reaction, and the results were correlated. A negative association was observed between miR-367-3p and CD69. CD, cluster of differentiation.

3'UTR (Fig. 2B). In contrast, cells co-transfected with miR-367-3p mimic + mutant1 CD69 3'UTR had comparable luciferase activity levels to the empty vector+ scramble control-transfected cells. The results indicated that CD69 is a direct target of miR-367-3p, with the binding site located at 758-765 bp on the 3'UTR of CD69.

Negative regulatory association between CD69 and $m i R-367-3 p$. The miRNA-mRNA regulatory association was further investigated by investigating the expression level of CD69 mRNA and the expression of miR-367-3p, determined by RT-qPCR analysis of CD69 and miR-367-3p levels in fibroblast cells. The results further indicated the existence of an association between miR-367-3p and CD69; the negative correlation coefficient was -0.50 ( $r=-0.50$; Fig. 3 ).

CD69 and miR-367-3p expression levels vary in different treatment groups. To further investigate the regulatory association between miR-367-3p and CD69, RT-qPCR and western blot analysis were used to determine the expression level of CD69 mRNA and protein in cells treated with miR-367-3p mimics or CD69 siRNA. CD69 mRNA (Fig. 4A) and protein (Fig. 4B) levels in cells transfected with miR-367-3p mimics or CD69 siRNA were reduced, compared with the scramble control. Notably, the CD69 mRNA and protein levels demonstrated similar alterations in expression levels, indicating 
A

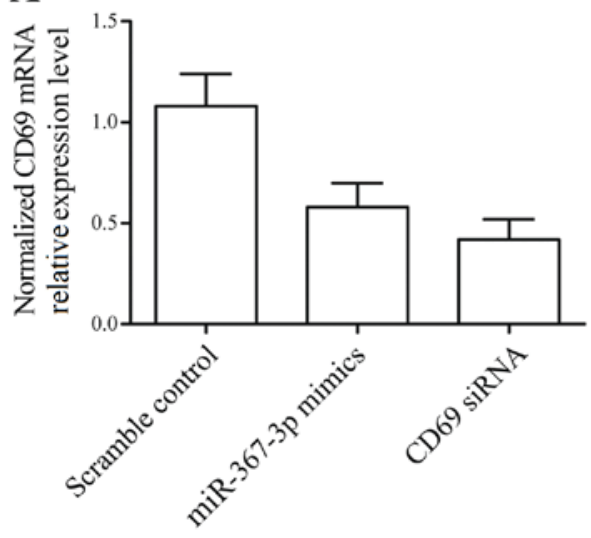

B
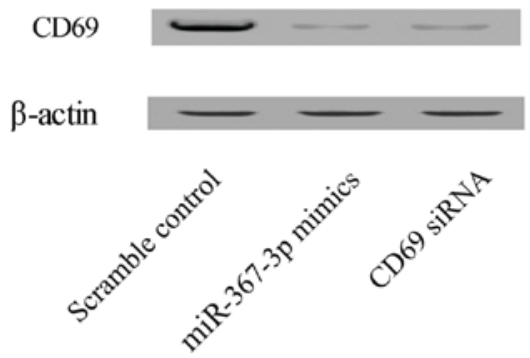

Figure 4. MiR-367-3p overexpression reduces CD69 mRNA and protein expression. CD69 (A) mRNA and (B) protein expression levels were investigated using reverse transcription-quantitative polymerase chain reaction and western blotting, respectively. Cells transfected with miR-367-3p mimics or CD69 siRNA exhibited decreased CD69 levels compared with the scramble control ( $\mathrm{P}<0.05$ vs. scramble control). CD, cluster of differentiation; miR, microRNA; siRNA, small interfering RNA.

A

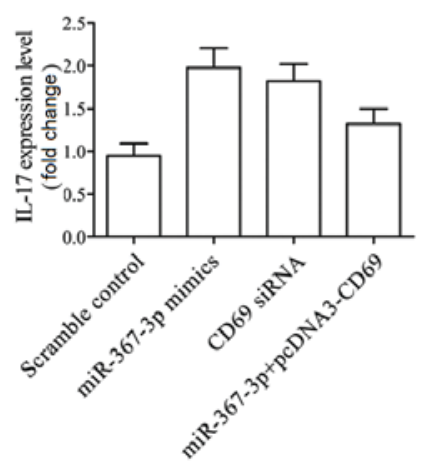

B

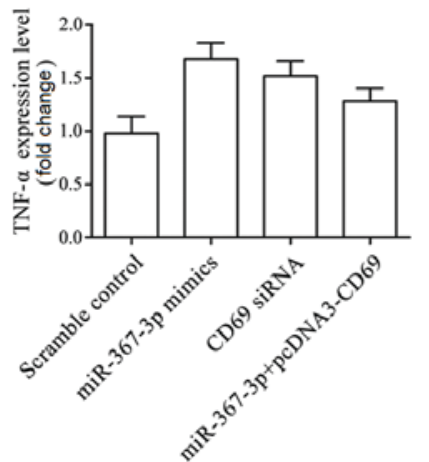

C

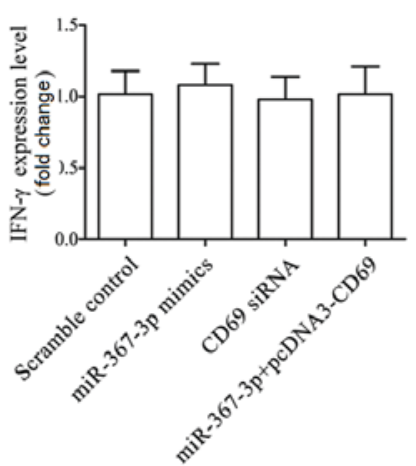

D

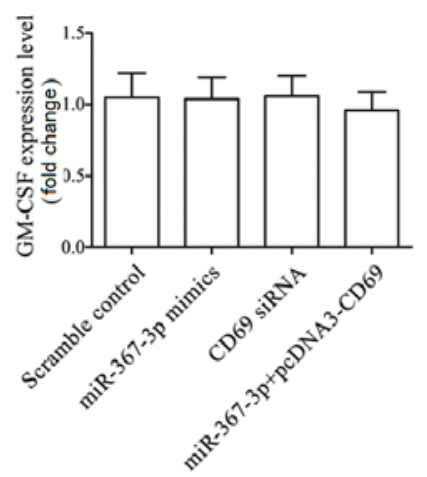

Figure 5. IL-17 and TNF- $\alpha$ levels are elevated by miR-367-3p via inhibition of CD69. Levels of (A) IL-17, (B) TNF- $\alpha$, (C) IFN- $\gamma$ and (D) GM-CSF were assessed by ELISA in cells transfected with scramble control, miR-367-3p, CD69 siRNA or miR-367-3p + pcDNA3-CD69. MiR-367-3p mimic and CD69 siRNA upregulated IL-17 and TNF- $\alpha$ levels compared with scramble control $(\mathrm{P}<0.05$ vs. scramble control), while IL-17 and TNF- $\alpha$ levels in miR-367-3p + pcDNA-CD69 group were comparable with scramble control. And miR-367-3p mimic and CD69 siRNA had no effect on IFN- $\gamma$ and GM-CSF levels. CD, cluster of differentiation; miR, microRNA; siRNA, small interfering RNA; IL-17, interleukin; TNF- $\alpha$, tumor necrosis factor- $\alpha$; IFN- $\gamma$, interferon- $\gamma$; GM-CSF, granulocyte macrophage colony-stimulating factor.

the negative regulatory association between miR-367-3p and CD69 is effective at the mRNA and protein level.

Levels of inflammatory factors vary in different treatment groups. Levels of IL-17, TNF- $\alpha$, IFN- $\gamma$ and GM-CSF of cells transfected with miR-367-3p, CD69 siRNA or miR-367-3p + pcDNA3-CD69 were investigated using cytokine ELISAs. The levels of IL-17 (Fig. 5A) and TNF- $\alpha$ (Fig. 5B) in cells transfected with miR-367-3p mimics or CD69 siRNA were markedly upregulated, compared with the scramble control and cells transfected with miR-367-3p + pcDNA3-CD69. Cells transfected with miR-367-3p + pcDNA3-CD69 demonstrated comparable IL-17 and TNF- $\alpha$ levels to the scramble control, indicating that miR-367-3P may impact upon the expression of IL-17 and TNF- $\alpha$ via inhibition of CD69. Notably, the levels of IFN- $\gamma$ (Fig. 5C) and GM-CSF (Fig. 5D) in cells transfected with miR-367-3p mimics, CD69 siRNA or pcDNA3-CD69 were comparable with the scramble control, indicating that miR-367-3P and CD69 had no impact on the expression of IFN- $\gamma$ and GM-CSF.
Th17 fraction of cells varied in different treatment groups. The Th17 fraction of cells transfected with miR-367-3p, CD69 siRNA or miR-367-3p + pcDNA3-CD69 were detected by flow cytometry using one-way ANOVA. The Th17 fraction of cells transfected with miR-367-3p mimics or CD69 siRNA was markedly upregulated, compared with the scramble control (Fig. 6). The Th17 fraction of cells transfected with miR-367-3p + pcDNA3-CD69 and scramble control were similar. These results indicated that miR-367-3P may increase the Th17 fraction, via inhibition of CD69 expression.

\section{Discussion}

Under normal homeostatic conditions, miRNAs serve several physiological roles, including limb morphogenesis, fat metabolism, hematopoiesis, cell apoptosis, proliferation and differentiation. However, in pathological conditions, aberrant miRNA levels regulate the expression of numerous genes to maintain the disease state. Previous bioinformatic predictions have indicated that miRNAs may regulate the expression 
of $\sim 90 \%$ genes, despite occupying only $3 \%$ of the human genome $(27,28)$. A single miRNA may potentially influence the expression of several target genes. MiR-21 may regulate the proliferation of fibroblasts and the development of fibrosis, and miR-29 exhibits an ability to reduce the expression of collagens $(29,30)$. Furthermore, miR-133 and miR-30 serve as regulators of connective tissue growth factor, thus resulting in decreased collagen production (31). However, the role of miRNAs in fibrosis following MI remains largely unknown. Investigating the role of miRNAs in the pathogenesis of cardiac disease may be useful in identifying novel therapies for MI, and other fibrotic cardiac diseases.

The present study performed RT-qPCR to estimate the expression of miR-367-3p and CD69 in patients with cardiac fibrosis [fibrosis $(+) ; \mathrm{n}=16$ ] and without cardiac fibrosis [fibrosis $(-) ; n=18]$. The results indicated that the expression level of miR-367-3p was decreased in the cardiac fibrosis (+) group, compared with the fibrosis (-) control group. In contrast, CD69 mRNA was enhanced in the fibrosis (+) group, compared with the fibrosis (-) control group. TargetScan and miRanda were employed to identify putative binding sites of miR-367-3p, which yielded CD69 as a hypothetical target of this miRNA. CD69 was investigated as a target gene of miR-367-3p using a luciferase assay. The luciferase reporter assay was performed by transfecting cells with miR-367-3p mimics + wild-type 3'UTR of CD69, miR-367-3p mimics + mutant1 3'UTR of CD69, or miR-367-3p mimics + mutant2 3'UTR of CD69. The results indicated that luciferase activity was downregulated following transfection with miR-367-3p mimics and the wild-type 3'UTR or the mutant2 3'UTR of CD69, compared with the scramble control. However, there was no effect on the luciferase activity in cells transfected with miR-367-3p mimics and the mutant 1 3'UTR of CD69, indicating that the miR-367-3p binding site was located at 758-765 bp on the 3'UTR of CD69.

Increased concentrations of inflammatory mediators are consistently observed in experimental models with pressure overload-induced cardiac fibrosis; however, the inflammatory reaction intensity remains lower than that observed in infarcted hearts $(32,33)$. Fibrosis may be promoted by pro-inflammatory signals, via activation of resident cardiac fibroblasts, thus driving macrophages towards a fibrogenic phenotype and resulting in the recruitment of fibroblast progenitors and fibrogenic monocyte subsets. The transition from inflammation to fibrosis may be influenced by early alterations in the cardiac interstitial matrix $(34,35)$. The human differentiation antigen CD69 is initially expressed on the cell surface following activation of B lymphocytes, $\mathrm{T}$ cells and other hematopoietic-originated cells (36,37). CD69 is a disulphide-linked homodimer with two constitutively phosphorylated chains, which has been classified as a type II integral protein, with an extracellular C-type lectin superfamily domain (38-40). The CD69 gene is situated within the p13-p12 bands on human chromosome 12, a region which also contains the NK complex. CD69 is associated with other C-type lectin genes that control the activity of NK-cells, indicating that CD69 may also exert a variable influence on NK-cell function $(39,41,42)$. CD69 serves as a costimulatory molecule resulting in the induction of immune cell-mediated cytotoxicity, secretion and/or cell proliferation once expressed on T cells (13). NK cells rapidly express CD69 following activation, and the

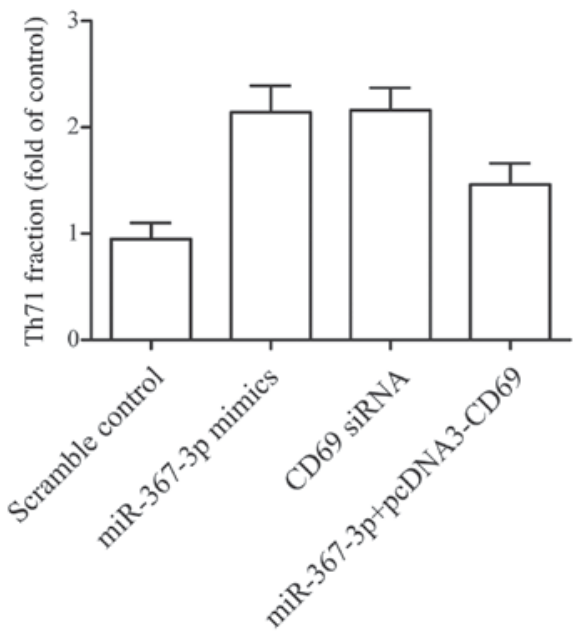

Figure 6 . The Th17 cell fraction is elevated by overexpression of miR-367-3p or inhibition of CD69. Cells transfected with miR-367-3p mimics and CD69 siRNA exhibited an elevated fraction of Th17 cells, compared with the scramble control ( $\mathrm{P}<0.05$ vs. scramble control). $\mathrm{CD}$, cluster of differentiation; Th, T helper; miR, microRNA; siRNA, small interfering RNA.

role of CD69 in NK-mediated cytotoxicity has been observed in mice and humans (43-47). However, further CD69-mediated roles in NK-cells are currently largely unknown. The present study performed RT-qPCR and western blot analysis to evaluate the CD69 mRNA and protein expression levels of cells transfected with miR-367-3p mimics and CD69 siRNA. The results indicated that the CD69 protein exhibited markedly reduced expression in the miR-367-3p mimics and CD69 siRNA-transfected treatment groups, compared with the scramble control. Analysis with cytokine ELISAs directed against IL-17, TNF- $\alpha$, IFN- $\gamma$ and GM-CSF in cells transfected with miR-367-3p, CD69 siRNA or miR-367-3p + pcDNA3-CD69, revealed that the IL-17 and TNF- $\alpha$ levels were elevated in cells transfected with miR-367-3p mimics or CD69 siRNA, compared with the scramble control and the miR-367-3p + pcDNA3-CD69-treated cells. The levels of IL-17 and TNF- $\alpha$ in cells transfected with miR-367-3p mimics and pcDNA3-CD69 were comparable with the scramble control. Notably, the IFN- $\gamma$ and GM-CSF levels of cells transfected with miR-367-3p mimics, CD69 siRNA and pcDNA3-CD69 were all comparable with the scramble control.

The Th17 fraction of cells transfected with miR-367-3p mimics, CD69 siRNA or miR-367-3p + pcDNA3-CD69 was investigated by flow cytometry. The results revealed an increase in the Th17 fraction of cells transfected with miR-367-3p mimics and CD69 siRNA, compared with the scramble control. In contrast, the Th17 fraction of cells transfected with miR-367-3p + pcDNA3-CD69 were similar to the fraction of Th17 cells in the scramble control. The increase in the Th17 fraction may be due to TNF- $\alpha$ functioning as an activator of Th17 pathways (48). miR-367-3P may effect the expression of TNF- $\alpha$ via inhibition of CD69, thus leading to an upregulation in the Th17 fraction.

In conclusion, the results of the present study provide support that downregulation of miR-367-3p may be associated with cardiac fibrosis.

\section{Acknowledgements}

Not applicable. 


\section{Funding}

No funding was received.

\section{Availability of data and materials}

The datasets used and/or analyzed during the current study are available from the corresponding author on reasonable request.

\section{Authors' contributions}

HH planned the study, collected, analyzed and interpreted the data, prepared the manuscript and approved the final manuscript; JL planned the study, prepared the manuscript, analyzed the literature and approved the final manuscript; JZ collected, analyzed and interpreted the data, analyzed the literature and approved the final manuscript.

\section{Ethics approval and consent to participate}

The ethics committee of the Second Affiliated Hospital of Xi'an Medical College approved the protocols of the study, and the research process was completed in conformity with the last version of the Declaration of Helsinki. Written informed consent was obtained prior to open-heart surgery for bypass grafting and general surgical procedures.

\section{Consent for publication}

Not applicable.

\section{Competing interests}

The authors declare they have no competing interests.

\section{References}

1. Berk BC, Fujiwara K and Lehoux S: ECM remodeling in hypertensive heart disease. J Clin Invest 117: 568-575, 2007.

2. Frangogiannis NG: Regulation of the inflammatory response in cardiac repair. Circ Res 110: 159-173, 2012.

3. Kong P, Christia P and Frangogiannis NG: The pathogenesis of cardiac fibrosis. Cell Mol Life Sci 71: 549-574, 2014.

4. van den Borne SW, Diez J, Blankesteijn WM, Verjans J, Hofstra L and Narula J: Myocardial remodeling after infarction: The role of myofibroblasts. Nat Rev Cardiol 7: 30-37, 2010.

5. Zamilpa R and Lindsey ML: Extracellular matrix turnover and signaling during cardiac remodeling following MI: Causes and consequences. J Mol Cell Cardiol 48: 558-563, 2010.

6. Tomasek JJ, Gabbiani G, Hinz B, Chaponnier C and Brown RA Myofibroblasts and mechano-regulation of connective tissue remodelling. Nat Rev Mol Cell Biol 3: 349-363, 2002.

7. Bujak M and Frangogiannis NG: The role of TGF-beta signaling in myocardial infarction and cardiac remodeling. Cardiovasc Res 74: 184-195, 2007.

8. Bartel DP: MicroRNAs: Genomics, biogenesis, mechanism, and function. Cell 116: 281-297, 2004.

9. Griffiths-Jones S: The microRNA registry. Nucleic Acids Res 32 (Database Issue): D109-D111, 2004

10. Chen JF, Mandel EM, Thomson JM, Wu Q, Callis TE, Hammond SM, Conlon FL and Wang DZ: The role of microRNA-1 and microRNA-133 in skeletal muscle proliferation and differentiation. Nat Genet 38: 228-233, 2006.

11. MartínP,GómezM,LamanaA,Cruz-Adalia A,Ramírez-Huesca M, Ursa MA, Yáñez-Mo M and Sánchez-Madrid F: CD69 association with Jak3/Stat5 proteins regulates Th17 cell differentiation. Mol Cell Biol 30: 4877-4889, 2010.
12. Shinoda K, Tokoyoda K, Hanazawa A, Hayashizaki K, Zehentmeier S, Hosokawa H, Iwamura C, Koseki H, Tumes DJ, Radbruch A and Nakayama T: Type II membrane protein CD69 regulates the formation of resting T-helper memory. Proc Natl Acad Sci USA 109: 7409-7414, 2012.

13. Alari-Pahissa E, Notario L, Lorente E, Vega-Ramos J, Justel A, López D, Villadangos JA and Lauzurica P: CD69 does not affect the extent of T cell priming. PLoS One 7: e48593, 2012.

14. Lieberman SM, Kim JS, Corbo-Rodgers E, Kambayashi T, Maltzman JS, Behrens EM and Turka LA: Site-specific accumulation of recently activated CD4+ Foxp3+ regulatory T cells following adoptive transfer. Eur J Immunol 42: 1429-1435, 2012.

15. Shiow LR, Rosen DB, Brdicková N, Xu Y, An J, Lanier LL, Cyster JG and Matloubian M: CD69 acts downstream of interferon-alpha/beta to inhibit S1P1 and lymphocyte egress from lymphoid organs. Nature 440: 540-544, 2006.

16. Lamana A, Martin P, de la Fuente H, Martinez-Muñoz L, Cruz-Adalia A, Ramirez-Huesca M, Escribano C, Gollmer K, Mellado M, Stein JV, et al: CD69 modulates sphingosine-1-phosphate-induced migration of skin dendritic cells. J Invest Dermatol 131: 1503-1512, 2011.

17. Sancho D, Gómez M, Viedma F, Esplugues E, Gordón-Alonso M, García-López MA, de la Fuente H, Martínez-A C, Lauzurica P and Sánchez-Madrid F: CD69 downregulates autoimmune reactivity through active transforming growth factor-beta production in collagen-induced arthritis. J Clin Invest 112: 872-882, 2003

18. Cruz-Adalia A, Jiménez-Borreguero LJ, Ramírez-Huesca M, Chico-Calero I, Barreiro O, López-Conesa E, Fresno M, Sánchez-Madrid F and Martín P: CD69 limits the severity of cardiomyopathy after autoimmune myocarditis. Circulation 122: 1396-1404, 2010

19. Radulovic K, Manta C, Rossini V, Holzmann K, Kestler HA, Wegenka UM, Nakayama T and Niess JH: CD69 regulates type I IFN-induced tolerogenic signals to mucosal CD4 T cells that attenuate their colitogenic potential. J Immunol 188: 2001-2013, 2012.

20. Gómez M, Sanz-González SM, Abu Nabah YN, Lamana A, Sánchez-Madrid F and Andrés V: Atherosclerosis development in apolipoprotein E-null mice deficient for CD69. Cardiovasc Res 81: 197-205, 2009.

21. Khallou-Laschet J, Caligiuri G, Groyer E, Tupin E, Gaston AT, Poirier B, Kronenberg M, Cohen JL, Klatzmann D, Kaveri SV and Nicoletti A: The proatherogenic role of T cells requires cell division and is dependent on the stage of the disease. Arterioscler Thromb Vasc Biol 26: 353-358, 2006.

22. Laffón A, García-Vicuña R, Humbría A, Postigo AA, Corbí AL, de Landázuri MO and Sánchez-Madrid F: Upregulated expression and function of VLA-4 fibronectin receptors on human activated T cells in rheumatoid arthritis. J Clin Invest 88: 546-552, 1991.

23. García-Monzón C, Moreno-Otero R, Pajares JM, García-Sánchez A, López-Botet M, de Landázuri MO and Sánchez-Madrid F: Expression of a novel activation antigen on intrahepatic CD8+ T lymphocytes in viral chronic active hepatitis. Gastroenterology 98: 1029-1035, 1990.

24. Khan M, Nickoloff E, Abramova T, Johnson J, Verma SK, Krishnamurthy P, Mackie AR, Vaughan E, Garikipati VN, Benedict C, et al: Embryonic stem cell-derived exosomes promote endogenous repair mechanisms and enhance cardiac function following myocardial infarction. Circ Res 117: 52-64, 2015.

25. Ong S, Ligons DL, Barin JG, Wu L, Talor MV, Diny N, Fontes JA, Gebremariam E, Kass DA, Rose NR and Čiháková D: Natural killer cells limit cardiac inflammation and fibrosis by halting eosinophil infiltration. Am J Pathol 185: 847-861, 2015

26. Livak KJ and Schmittgen TD: Analysis of relative gene expression data using real-time quantitative PCR and the 2(-Delta Delta C(T)) method. Methods 25: 402-408, 2001.

27. Pauley KM, Cha S and Chan EK: MicroRNA in autoimmunity and autoimmune diseases. J Autoimmun 32: 189-194, 2009.

28. Miranda KC, Huynh T, Tay Y, Ang YS, Tam WL, Thomson AM, Lim B and Rigoutsos I: A pattern-based method for the identification of MicroRNA binding sites and their corresponding heteroduplexes. Cell 126: 1203-1217, 2006.

29. Thum T, Gross C, Fiedler J, Fischer T, Kissler S, Bussen M, Galuppo P, Just S, Rottbauer W, Frantz S, et al: MicroRNA-21 contributes to myocardial disease by stimulating MAP kinase signalling in fibroblasts. Nature 456: 980-984, 2008 
30. van Rooij E, Sutherland LB, Thatcher JE, DiMaio JM, Naseem RH, Marshall WS, Hill JA and Olson EN: Dysregulation of microRNAs after myocardial infarction reveals a role of miR-29 in cardiac fibrosis. Proc Natl Acad Sci USA 105: 13027-13032, 2008.

31. Duisters RF, Tijsen AJ, Schroen B, Leenders JJ, Lentink V, van der Made I, Herias V, van Leeuwen RE, Schellings MW, Barenbrug $\mathrm{P}$, et al: $\mathrm{miR}-133$ and $\mathrm{miR}-30$ regulate connective tissue growth factor: Implications for a role of microRNAs in myocardial matrix remodeling. Circ Res 104: 170-178, 6p following 178, 2009.

32. Nicoletti A, Heudes D, Mandet C, Hinglais N, Bariety J and Michel JB: Inflammatory cells and myocardial fibrosis: Spatial and temporal distribution in renovascular hypertensive rats. Cardiovasc Res 32: 1096-1107, 1996.

33. Xia Y, Lee K, Li N, Corbett D, Mendoza L and Frangogiannis NG: Characterization of the inflammatory and fibrotic response in a mouse model of cardiac pressure overload. Histochem Cell Biol 131: 471-481, 2009.

34. Schellings MW, Pinto YM and Heymans S: Matricellular proteins in the heart: Possible role during stress and remodeling. Cardiovasc Res 64: 24-31, 2004.

35. Frangogiannis NG: Matricellular proteins in cardiac adaptation and disease. Physiol Rev 92: 635-688, 2012.

36. Testi R, D'Ambrosio D, De Maria R and Santoni A: The CD69 receptor: A multipurpose cell-surface trigger for hematopoietic cells. Immunol Today 15: 479-483, 1994.

37. Lu H, Crawford RB, North CM, Kaplan BL and Kaminski NE: Establishment of an immunoglobulin $\mathrm{m}$ antibody-forming cell response model for characterizing immunotoxicity in primary human B cells. Toxicol Sci 112: 363-373, 2009.

38. Hamann J, Fiebig H and Strauss M: Expression cloning of the early activation antigen CD69, a type II integral membrane protein with a C-type lectin domain. J Immunol 150: 4920-4927, 1993.

39. López-Cabrera M, Santis AG, Fernández-Ruiz E, Blacher R, Esch F, Sánchez-Mateos P and Sánchez-Madrid F: Molecular cloning, expression, and chromosomal localization of the human earliest lymphocyte activation antigen AIM/CD69, a new member of the C-type animal lectin superfamily of signal-transmitting receptors. J Exp Med 178: 537-547, 1993.
40. Ziegler SF, Ramsdell F, Hjerrild KA, Armitage RJ Grabstein KH, Hennen KB, Farrah T, Fanslow WC, Shevach EM and Alderson MR: Molecular characterization of the early activation antigen CD69: A type II membrane glycoprotein related to a family of natural killer cell activation antigens. Eur J Immunol 23: 1643-1648, 1993.

41. Ziegler SF, Levin SD, Johnson L, Copeland NG, Gilbert DJ, Jenkins NA, Baker E, Sutherland GR, Feldhaus AL and Ramsdell F: The mouse CD69 gene. Structure, expression, and mapping to the NK gene complex. J Immunol 152: 1228-1236, 1994.

42. Schnittger S, Hamann J, Dannenberg C, Fiebig H, Strauss M and Fonatsch C: Regional sublocalization of the human CD69 gene to chromosome bands $12 \mathrm{p} 12.3-\mathrm{p} 13.2$, the predicted region of the human natural killer cell gene complex. Eur J Immunol 23: 2711-2713, 1993.

43. Borrego F, Peña J and Solana R: Regulation of CD69 expression on human natural killer cells: Differential involvement of protein kinase $\mathrm{C}$ and protein tyrosine kinases. Eur J Immunol 23: 1039-1043, 1993.

44. Bezouska K, Nepovím A, Horváth O, Pospísil M, Hamann J and Feizi T: CD 69 antigen of human lymphocytes is a calcium-dependent carbohydrate-binding protein. Biochem Biophys Res Commun 208: 68-74, 1995.

45. Gerosa F, Tommasi M, Benati C, Gandini G, Libonati M, Tridente G, Carra G and Trinchieri G: Differential effects of tyrosine kinase inhibition in CD69 antigen expression and lytic activity induced by rIL-2, rIL-12, and rIFN-alpha in human NK cells. Cell Immunol 150: 382-390, 1993.

46. Felts JM, Itakura H and Crane RT: The mechanism of assimilation of constituents of chylomicrons, very low density lipoproteins and remnants-a new theory. Biochem Biophys Res Commun 66: 1467-1475, 1975.

47. Karlhofer FM and Yokoyama WM: Stimulation of murine natural killer (NK) cells by a monoclonal antibody specific for the NK1.1 antigen. IL-2-activated NK cells possess additional specific stimulation pathways. J Immunol 146: 3662-3673, 1991.

48. Luan L, Han S, Wang H and Liu X: Down-regulation of the Th1, Th17, and Th22 pathways due to anti-TNF- $\alpha$ treatment in psoriasis. Int Immunopharmacol 29: 278-284, 2015. 